\title{
DIAGNOSING PERIPHERAL ARTERIAL DISEASE IN PATIENTS WITH KNOWN CORONARY ARTERY DISEASE IN A TERTIARY CARE CENTER IN LAHORE AND ASSESSING DIAGNOSTIC ACCURACY OF ANKLE - BRACHIAL INDEX TAKING DUPLEX ULTRASOUND AS GOLD STANDARD
}

\author{
Nauman Naseer, ${ }^{1}$ Ahmed Hassan, ${ }^{2}$ Zeeshan Ghous ${ }^{3}$
}

\section{Introduction}

It is common for patients with PAD to have concomitant CAD because both are caused by atherosclerosis, a systemic process. This has been well established in international studies. The incidence of PAD in patients with known CAD in our population is unknown. The ankle - brachial index (ABI) can be calculated by taking the ratio of ankle systolic pressure and brachial systolic pressure. It is a simple, easy and cost effective bedside tool to diagnose peripheral arterial disease (PAD).

Objective: The objective of the study was to:

\section{Naseer N. ${ }^{1}$}

Associate Professor of Cardiology

University of Health Sciences, Lahore

Hassan A. ${ }^{2}$

Senior Register Department of Cardiology

Jinnah Hospital, Lahore

Ghous Z. ${ }^{3}$

Registrar Department of Cardiology

Jinnah Hospital, Lahore
- Determine the incidence of PAD in patients with known coronary artery disease (CAD) in our population.

- Determine the diagnostic accuracy of $\mathrm{ABI}$ in diagnosing PAD in patients with CAD taking duplex ultrasound as gold standard in local population.

Study Design: Cross sectional study.

Setting: Department of Cardiology (CCU), Jinnah Hospital, Lahore.

Study Duration: Six months from 01 June 2014 to 31 December 2014.

Subjects and Methods: 310 patients who met the inclusion / exclusion criteria were entered in the study. Mercury sphygmomanometer was used to take the systolic blood pressure of all the four limbs, and the ratio of ankle systolic pressure (higher of systolic pressure taken in both left and right limb was taken) to brachial systolic pressure (higher of systolic pressure taken in both left and right limb was taken) was used to calculate the ABI. An abnormal ABI was considered if the ratio was < 0.9. All subjects underwent duplex ultrasound as a gold standard to detect the presence or absence of PAD.

Results: Out of 310 cases, common age was calculated as $59.21 \pm 8.93$ years, $53.23 \%(\mathrm{n}=165)$ were male 
while $46.77 \%(n=145)$ were female, frequency of peripheral artery disease (PAD) on gold standard was recorded as $28.71 \%(\mathrm{n}=89)$, diagnostic accuracy of Ankle-Brachial Index (ABI) in diagnosing peripheral artery disease (PAD) in patients with coronary artery disease (CAD) was calculated as 93.25\%, 94.21\%, $86.46 \%, 97.20 \%$ and $93.87 \%$ as specificity, sensitivity, negative predictive value, positive predictive value and accuracy rate respectively.

Conclusion: There is a $28.7 \%$ incidence of PAD in patients with known CAD in our study population. The $\mathrm{ABI}$ is a simple, easy low cost and yet underutilized tool that can detect PAD with high diagnostic accuracy in this population.

Keywords: Coronary artery disease (CAD), peripheral artery disease (PAD), diagnosis, ankle - brachial index (ABI), accuracy

\section{Introduction}

PAD is a common pathology used to describe the limitation of blood flow, especially to the lower extremities, that is usually as a result of atherosclerotic disease $^{1}$ and associated with substantial morbidity and mortality. ${ }^{2}$ Certain risk factors i.e., Diabetes Mellitus, smoking, hypertension and hypercholesterolemia are commonly present in patients who suffer from PAD. PAD is equally prevalent in men and women. It is common for patients with PAD to have concomitant a CAD and carotid artery disease. All patients with PAD should be considered for evaluation of coronary artery and carotid artery disease. ${ }^{3}$ PAD is associated with an increased incidence of multi vessel and obstructive CAD. $^{4}$

The ABI is calculated by dividing the highest systolic B.P in the ankle (among both right and left lower limb) to the highest systolic B.P of the brachial artery (among right and left upper limb). It is a simple, noninvasive tool with high specificity and sensitivity for the diagnosis of PAD. ${ }^{5-6}$

The majority PAD patients have concomitant CAD. A large burden of morbidity and mortality in patients with PAD is related to cardiovascular events such as myocardial infarction (MI), ischemic stroke, or cardiovascular death. ${ }^{2}$ Indeed, in a series of 1,000 coronary angiograms of patients who were under consideration for vascular surgery for abdominal aortic aneurysm $(n=263)$, carotid artery disease $(n=295)$, or PAD $(n=381)$ only $8 \%$ demonstrated normal coronary arteries. Also noteworthy is that patients with
PAD but no clinical evidence of CAD have similar rate of death from cardiovascular causes as those with known CAD, which is consistent with the systemic nature of the disease. ${ }^{2}$

Both the CAD as well as PAD may be found concomitantly in same patients and its prevalence was evaluated in two studies REACH registry and the AGATHA study in which it was found that $16-35 \%$ of patients who had $\geq 3$ risk factors or had documented atherosclerotic disease also suffered from multivascular disease. Significant obstructive single vessel CAD has been reported in $60 \%$ of patients that had severe lower limb PAD that require surgery. ${ }^{7-8} \mathrm{DM}$, smoking, elevated B.P, elevated cholesterol level and elevated CRP constitute the common risk factors for atherosclerotic disease that are associated with PAD out of which smoking and diabetes have the strongest correlation $(2-4$ fold $)$ with PAD.

When the concomitant existence of PAD and CAD is compared with their existence as separate disease it is found that all - cause mortality due to concomitant existence reaches up to $4.6 \%$ per year which is almost double as compared with either disease alone. In REA$\mathrm{CH}$ registry it was found that the annual risk of allcause mortality was $23.1 \%$ in the concomitant PAD and CAD but either of the disease alone had the risk of $13-17 \%$. Results of the CASS registry showed that PADwas seen as more potent predictor of morbidity and mortality as compared to prior myocardial infarction or angina pectoris severity.

An ABI $<0.90$ has excellent specificity (98\%) and sensitivity (90\%) for detecting a lower - extremity stenosis of greater than $50 \% .^{09,10}$ The American College of Cardiology (ACC) and the American Heart Association (AHA) guide lines provide further details on use of ABI. Interpretation of different values of $\mathrm{ABI}$ is given below: ${ }^{11}$

- $0.00-0.40$ : Severe PAD.

- $0.41-0.90$ : PAD present and it will cause claudication.

- $\quad 0.91-1.30$ : taken as Normal vessels.

- 1.30: Non compressible or severely calcified vessel.

\section{Material and Methods}

Study Design: Cross sectional study.

Setting: Department of Cardiology (CCU), Jinnah Hospital, Lahore. 


\section{Study Duration:}

- Six months from:

01-07-2014 to 31-12-2014.

\section{Sample Size}

- 310 patients.

\section{Sampling Technique}

- Non probability, purposive sampling.

\section{Inclusion Criteria}

- $\quad$ Age ( $\geq 40$ years).

- Male and Female.

- Angiographic evidence of significant CAD, i.e. $>50 \%$ stenosis.

\section{Exclusion Criteria}

- Already diagnosed cases of PAD.

- Patients with previous limb vascular procedures.

\section{Data Collection Procedure}

All 310 patients fulfilling the inclusion/exclusion criteria presenting to Department of Cardiology, Jinnah Hospital, Lahore were enrolled after informed consent. Measurement of systolic B.P of all the four limbs was done in all the patients that were included in the study. Mercury sphygmomanometer was used for this purpose. B.P was taken in a quiet room when the patient was in a supine position after the relaxation period of at least $5 \mathrm{~min}$. Right as well as left arm and ankle systolic blood pressures were measured using a manually operated blood pressure withthe cuff width, being at a minimum, 20\% > than the diameter of the extremity.A cycle of measurements (right arm, right ankle, left ankle, left arm) weredone. Doppler device with ultrasound gel was used to detect pulses. Finally, the ratio was taken between higher systolic B.P of the ankle and the higher systolic B.P of the brachial artery. This ratio was used for the calculation ABI. An ABI of $<0.9$ was considered as abnormal and indicative of PAD. All subjects also underwent duplex ultrasoundof lower extremities as a gold standard to detect the presence or absence of PAD. The criteria for significant PAD with $50-99 \%$ stenosis were monophasic flow, spectral broadening and peak systolic flow distal to proximal peak systolic flow ratio $2: 1{ }^{14}$ There were two cardiovascular physicians who were dedicated to doing these doppler studies and were blinded to ABI results.

\section{Data Analysis}

The data was entered in computer software SPSS version 11.0. Categorical variables e.g. gender and presence of PAD was described as frequency and percenttages. Continuous variables e.g. age were described as mean \pm S.D. A $2 \times 2$ table was drawn and diagnostic accuracy of ABI was calculated followed by calculating positive and negative predictive value, sensitivity as well as specificity taking duplex scan as diagnostic test.

\section{Results}

Age distribution of the patients was done which shows that $61.29 \%(\mathrm{n}=190)$ were between $41-60$ years of age while $38.71 \%(\mathrm{n}=120)$ were between $61-80$ years of age, mean \pm sd was calculated as $59.21 \pm 8.93$ years (Table 1).

Patients were distributed according to gender sho-

Table 1: Age Distribution of the Patients $(n=310)$.

\begin{tabular}{|c|c|c||}
\hline Age(in Years) & No. of Patients & $\%$ \\
\hline $41-60$ & 190 & 61.29 \\
\hline \hline $61-80$ & 120 & 38.71 \\
\hline \hline Total & 310 & 100 \\
\hline
\end{tabular}

Mean \pm SD: $59.21 \pm 8.93$

Table 2: Gender Distribution $(\mathrm{n}=310)$.

\begin{tabular}{|l|c|c|}
\hline \hline Gender & No. of Patients & $\%$ \\
\hline \hline Male & 165 & 53.23 \\
\hline \hline Female & 145 & 46.77 \\
\hline \hline Total & 310 & 100 \\
\hline
\end{tabular}

Table 3: Frequency of Peripheral Artery Disease (PAD) in Patients with Coronary Artery Disease (Cad) on Gold Standard $(\mathrm{n}=310)$.

\begin{tabular}{||l||c||c||}
\hline \hline PAD & No. of Patients & $\%$ \\
\hline \hline Yes & 89 & 28.71 \\
\hline \hline No & 221 & 71.29 \\
\hline \hline Total & 310 & 100 \\
\hline
\end{tabular}


wing that $53.23 \%(\mathrm{n}=165)$ were male while $46.77 \%$ $(\mathrm{n}=145)$ were female (Table 2$)$.

Frequency of peripheral artery disease (PAD) in patients with coronary artery disease (CAD) on gold standard was recorded as $28.71 \%(\mathrm{n}=89)$ and $71.29 \%$ $(n=221)$ had no findings of PAD (Table 3$)$.

Diagnostic accuracy of Ankle - Brachial Index $(\mathrm{ABI})$ in diagnosing peripheral artery disease (PAD) in patients with coronary artery disease (CAD) taking duplex ultrasound as gold standard was calculated as $93.25 \%, 94.21 \%, 86.46 \%, 97.20 \%$ and $93.87 \%$ as sensitivity, specificity, positive predictive value, negative predictive value and accuracy rate respectively (Table 4).

Stratification for frequency of peripheral artery disease with regards to age is calculated and presented in (Table 5).

Stratification for frequency of peripheral artery

Table 4: Diagnostic Accuracy of Ankle - Brachial Index (ABI) in Diagnosing Peripheral Artery Disease (Pad) In Patients With Coronary Artery Disease (Cad) Taking Duplex Ultrasound As Gold Standard $(\mathrm{n}=310)$.

Positive predictive value $=86.46 \%$

Negative predictive value $=97.20 \%$

Sensitivity $=93.25 \%$, Specificity $=94.21 \%$

Accuracy rate $=93.87 \%$

\begin{tabular}{|c|c|c|c|}
\hline \multirow{2}{*}{$\mathrm{ABI}$} & \multicolumn{2}{|c|}{ DUPLEX ULTRASOUND } & \multirow{2}{*}{ Total } \\
\hline & PAD (Positive) & PAD (Negative) & \\
\hline Positive & $\begin{array}{l}\text { True positive (a) } \\
83(26.77 \%)\end{array}$ & $\begin{array}{l}\text { False positive (b) } \\
13(4.19 \%)\end{array}$ & $\begin{array}{l}a+b \\
96(30.97 \%)\end{array}$ \\
\hline Negative & $\begin{array}{l}\text { False negative (c) } \\
6(1.94 \%)\end{array}$ & $\begin{array}{l}\text { True negative (d) } \\
208(67.09 \%)\end{array}$ & $\begin{array}{l}c+d \\
219(69.03 \%)\end{array}$ \\
\hline Total & $\begin{array}{l}a+c \\
89(28.71 \%)\end{array}$ & $\begin{array}{l}b+d \\
221(71.29 \%)\end{array}$ & $310(100 \%)$ \\
\hline
\end{tabular}

Table 5: Diagnostic Accuracy of Ankle - Brachial Index (ABI) in Diagnosing Pad in Patients with Cad with Regards to Age (Age: $41-60$ years).

\begin{tabular}{|c|c|c|c|}
\hline \multirow{2}{*}{$\mathrm{ABI}$} & \multicolumn{2}{|c|}{ DUPLEX ULTRASOUND } & \multirow{2}{*}{$P$ value } \\
\hline & Yes & No & \\
\hline Yes & $\begin{array}{c}\text { (True positive) } \\
51\end{array}$ & $\begin{array}{c}\text { (False positive) } \\
7\end{array}$ & \multirow{2}{*}{0.000} \\
\hline No & $\begin{array}{c}\text { (False negative) } \\
3\end{array}$ & $\begin{array}{c}\text { (True negative) } \\
129\end{array}$ & \\
\hline
\end{tabular}

Sensitivity $=94.44 \%$, Specificity $=94.85 \%$

Positive predictive value $=87.93 \%$

Negative predictive value $=97.73 \%$

Age: $61-80$ years

\begin{tabular}{|c|c|c|c|}
\hline \multirow{2}{*}{$\mathrm{ABI}$} & \multicolumn{2}{|c|}{ DUPLEX ULTRASOUND } & \multirow{2}{*}{$P$ value } \\
\hline & Yes & No & \\
\hline Yes & $\begin{array}{c}\text { (True positive) } \\
32\end{array}$ & $\begin{array}{c}\text { (False positive) } \\
6\end{array}$ & \multirow{2}{*}{0.000} \\
\hline No & $\begin{array}{c}\text { (False negative) } \\
3\end{array}$ & $\begin{array}{c}\text { (True negative) } \\
79\end{array}$ & \\
\hline
\end{tabular}

Sensitivity $=91.43 \%$, Specificity $=92.94 \%$

Positive predictive value $=84.21 \%$

Negative predictive value $=96.34 \%$
Table 6: Diagnostic Accuracy of Ankle - Brachial Index (ABI) in Diagnosing Peripheral Artery Disease (PAD) in Patients with Coronary Artery Disease (CAD) with Regards to Gender.

Male

\begin{tabular}{|c|c|c|c|}
\hline \multirow{2}{*}{$\mathrm{ABI}$} & \multicolumn{2}{|c|}{ DUPLEX ULTRASOUND } & \multirow{2}{*}{$\mathrm{P}$ value } \\
\hline & Yes & No & \\
\hline Yes & $\begin{array}{c}\text { (True positive) } \\
46\end{array}$ & $\begin{array}{c}\text { (False positive) } \\
4\end{array}$ & \multirow{2}{*}{0.000} \\
\hline No & $\begin{array}{c}\text { (False negative) } \\
3\end{array}$ & $\begin{array}{c}\text { (True negative) } \\
112\end{array}$ & \\
\hline
\end{tabular}

Sensitivity $=93.88 \%$, Specificity $=96.55 \%$, Positive predictive value $=92 \%$, Negative predictive value $=97.39 \%$

Female

\begin{tabular}{|c|c|c|c|}
\hline \multirow{2}{*}{$\mathrm{ABI}$} & \multicolumn{2}{|c|}{ DUPLEX ULTRASOUND } & \multirow{2}{*}{$P$ value } \\
\hline & Yes & No & \\
\hline Yes & $\begin{array}{c}\text { (True positive) } \\
37\end{array}$ & $\begin{array}{c}\text { (False positive) } \\
9\end{array}$ & \multirow{2}{*}{0.000} \\
\hline No & $\begin{array}{c}\text { (False negative) } \\
3\end{array}$ & $\begin{array}{c}\text { (True negative) } \\
96\end{array}$ & \\
\hline
\end{tabular}

Sensitivity $=92.5 \%$, Specificity $=91.43 \%$

Positive predictive value $=80.43 \%$

Negative predictive value $=96.97 \%$ 
disease with regards to gender is calculated and presented in (Table 6).

\section{Discussion}

Cardiovascular disease burden on our society is immense. It is the leading cause of death worldwide. PAD is considered as the risk factor for the coronary artery disease that can be diagnosed by simple and cost effective test like ABI. The ABI of $\leq 0.90$ shows the existence PAD that affect the limb. The ABI is such a simple tool that it can detect PAD both in symptomatic as well as asymptomatic patients. Unfortunately, no study has been done on this topic locally, and there is variability regarding thisin international studies.

In our study, out of 310 cases, $61.29 \%(n=190)$ were between $41-60$ years of age while $38.71 \%$ ( $n=$ 120) were between $61-80$ years of age, mean \pm sd was calculated as $59.21 \pm 8.93$ years, $53.23 \%(\mathrm{n}=$ $165)$ were male while $46.77 \%(n=145)$ were female, frequency of PAD in patients with CAD on gold standard was recorded as $28.71 \%(n=89)$. The prevalence of significant CAD in patients with severe PAD varies widely from $55 \%$ to $72 \%^{13}$ in published reports but vice versa is not true. The prevalence of newly revealed abnormal, asymptomatic ABI among patients who have significant $\mathrm{CAD}$ on coronary angiography was $16-17 \%$ in other studies. ${ }^{14-15}$

The diagnostic accuracy of Ankle-Brachial Index (ABI) in diagnosis of PAD in patients with CAD taking duplex ultrasound as gold standard was calculated as $93.25 \%, 94.21 \%, 86.46 \%, 97.20 \%$ and $93.87 \%$ as sensitivity, specificity, positive predictive value, negative predictive value and accuracy rate respectively.

The findings of our study are in contrast with the findings of $M$. Premanath and M. Raghunath who recorded sensitivity and specificity of $\mathrm{ABI} \leq 0.90$ for the diagnosis of PAD and the level of sensitivity $(70.0 \%)$ and specificity $(75.0 \%)$ was reported for an $\mathrm{ABI} \leq 0.90$ in detecting $\geq 50 \%$ stenosis. $^{6}$

Another study by Dachun X and his colleagues in Chinese population and recorded a high level of sensitivity $(79 \%)$ and specificity (99\%) for an $\mathrm{ABI} \leq 0.90$ in detecting $\geq 50 \%$ stenosis, ${ }^{5}$ which is in accordance with our study.

$\mathrm{Xu} \mathrm{D}$ and others ${ }^{12}$ reported that ankle brachial index $(\mathrm{ABI}) \leq 0.90$ could reliably identify patients with peripheral artery disease (PAD). More and more studies have been published since then and their metaanalysis has shown the diagnostic accuracy of ABI.
Since then, more studies have been published which may extend the power of a meta-analysis of studies of diagnostic accuracy of the ABI. For the diagnosis PAD angiography was compared with the $\mathrm{ABI} \leq 0.9$ and to find the sensitivity as well as the specificity of ABI, in different studies for which search was made on MEDLINE and several other databases. They concluded that in clinical practice $\mathrm{ABI} \leq 0.90$ can be taken as reference for the diagnosis of the peripheral arterial disease.

In another study ${ }^{16}$ was done by Guo $\mathrm{X}$ and colleagues. They wanted to evaluate the positive likelihood ratio, negative likelihood ratio, sensitivity as well as specificity of $\mathrm{ABI}$ and used digital subtraction angiography (DSA) as gold standard for reference. They found that cutoff value of ABI for the diagnosis of PAD was 0.95 and its sensitivity was $91 \%$ and specificity was $86 \%$. They said in their concluding remarks that measurement of ABI is a reliable as well as accurate tool that is noninvasive and is good alternative to conventional DSA.The cut-off value for diagnosis of PAD is 0.95 .

\section{Conclusion}

There is a $28.7 \%$ incidence of PAD in patients with known CAD in our study population. The ABI is a simple, easy low cost and yet underutilized tool that can detect PAD with high diagnostic accuracy in this population.

\section{References}

1. Wassel CL, Loomba R, Ix JH, Allison MA, Denenberg JO, Criqui MH. Family history of peripheral artery disease is associated with prevalence and severity of peripheral artery disease: the San Diego population study. J Am Coll Cardiol. 2011; 58: 1386-92.

2. Hirsch AT, Haskal ZJ, Hertzer NR. ACC/AHA 2005 Practice Guidelines for the management of patients with peripheral arterial disease (lower extremity, renal, mesenteric, and abdominal aortic): a collaborative report from the American Association for Vascular Surgery / Society for Vascular Surgery, Society for Cardiovascular Angiography and Interventions, Society for Vascular Medicine and Biology, Society of Interventional Radiology, and the ACC/AHA Task Force on Practice Guidelines (Writing Committee to Develop Guidelines for the Management of Patients With Peripheral Arterial Disease): endorsed by the American Association of Cardiovascular and Pulmonary Reha- 
bilitation; National Heart, Lung, and Blood Institute; Society for Vascular Nursing; Trans Atlantic Inter-Society Consensus; and Vascular Disease Foundation. Circulation, 2006; 113: e463.

3. Mohler ER. Screening for Peripheral Artery Disease. Circulation, 2012; 126: e11-2.

4. Nunez D, Morillas P, Quiles J, Cordero A, Guindo J, Soria F. Usefulness of an abnormal ankle - brachial index for detecting multivessel coronary disease in patients with acute coronary syndrome. Rev Esp Cardiol. 2010; 63 (1): 54-9.

5. Dachun X, Jue L, Liling Z, Yawei X, Dayi H, Pagoto SL. Sensitivity and specificity of the ankle - brachial index to diagnose peripheral artery disease: a structured review. Vasc Med. 2010; 15 (5): 361-9.

6. M Premanath, M Raghunath. Ankle brachial index by oscillometry: A very useful method to assess peripheral arterial disease in diabetes. Int J Diabetes, 2010; 30 (2): 97-101.

7. Brueseke, TJ, Macrino, S and Miller JJ. Lack of lower extremity hair not a predictor for peripheral arterial disease. Arch. Dermatol. 2009; 145: 1456-57.

8. Shanmugasundaram M, Ram VK, Luft UC, Szerlip M, Alpert JS. Peripheral arterial disease - what do we need to know? Clin Cardiol. Jun. 29, 2011.

9. Yao ST, Hobbs JT, Irvine WT. Ankle systolic pressure measurements in arterial disease affecting the lower extremities. Br J Surg. Sep. 1969; 56 (9): 676-9.

10. Ouriel K, McDonnell AE, Metz CE, Zarins CK. Critical evaluation of stress testing in the diagnosis of peripheral vascular disease. Surgery. Jun. 1982; 91 (6): 686-93.

11. Newton EJ, Arora S. Peripheral vascular injury. In: Marx JA. Marx: Rosen's Emergency Medicine: Concepts and Clinical Practice. Vol 1. $7^{\text {th }}$ ed. Philadelphia: Saunders Elsevier; 2009: Part II - Trauma.

12. Xu D, Zou L, Xing Y, Hou L, Wei Y, Zhang J, et al. Diagnostic value of ankle - brachial index in peripheral arterial disease: a meta-analysis. Can J Cardiol. 2013; 29 (4): 492-8.

13. Shimada T, Toyoda K, Inoue T, Kamouchi M, Matsumoto T, Hiyamuta K, Imaizumi T, Okada Y. Prediction of coronary artery disease in patients undergoing carotid endarterectomy. J Neurosurg. 2005; 103: 593-596.

14. Imori $\mathrm{Y}$, Akasaka $\mathrm{T}$, Ochiai $\mathrm{T}$, Oyama K, Tobita K, Shishido K, Nomura Y et al. Co-existence of carotid artery disease, renal artery stenosis, and lower extremity peripheral arterial disease in patients with coronary artery disease. Am J Cardiol. 2014 Jan. 1; 113 (1): 30-5.

15. Guo X, Li J, Pang W, Zhao M, Luo Y, Sun Y, Hu D. Sensitivity and specificity of ankle - brachial index for detecting angiographic stenosis of peripheral arteries. Circ J. 2008 Apr; 72 (4): 605-10. 